\title{
Observations on the Control of Grain Size in Magnesium Casting Alloys
}

\author{
By Vernon C. F. Holm and Alexander I. Krynitsky
}

\begin{abstract}
The methods investigated for the control of grain size in magnesium casting alloys were (1) stirring of carbonaceous solids into the molten alloy, (2) bubbling of carbon monoxide through the melt, (3) melting in a silicon carbide crucible, and (4) treatment with lump magnesite. In the last method, the magnesite was placed deep in the molten metal, where it dissociated thermally, generating a carbonaceous gas that bubbled through the melt. The grain size and tensile properties were determined on specimens from each melt, and these were compared with data from melts that had been superheated as well as those that had received no special treatment. The results indicate that magnesium alloys that have been properly treated with carbonaceous materials possessed grain-size and tensile properties equivalent to those obtained in superheated metal. The magnesite method is a simple, inexpensive, and convenient means of developing a fine-grained structure in magnesium casting alloys.
\end{abstract}

\section{Introduction}

It is well known that castings of magnesium alloys tend to have a coarse-grained structure unless suitable steps are taken to insure the development of fine grains. The usual method for producing fine-grained structure has been to superheat the molten metal, a procedure initially described in 1931 in a British patent [1]. ${ }^{1}$ Superheating, in general, consists in heating a molten magnesium alloy to $250^{\circ}$ or $300^{\circ} \mathrm{C}$ above the liquidus, and after holding it there for a required period, cooling it to the desired temperature and pouring without delay. In recent years, with the increasing interest in magnesium casting alloys, other procedures have been proposed to accomplish this end and thereby avoid some of the disadvantages of superheating. Most of these involve treatment of the molten metal with carbon or a carbon compound. Natural gas [2, 4], acetylene $[2,4]$, carbon monoxide [5], carbon dioxide $[2,5,6]$, and a combination of chlorine and carbon tetrachloride $[2,3]$ have been recommended for bubbling through the molten metal. Mechanical agitation [4] alone and with additions of finely divided solid carbonaceous matter [6]

1 Figures in brackets indicate the literature references at the end of this paper.

Grain Size in Magnesium Casting Alloys like coal, peat, graphite, coke, etc., has also been proposed. A process involving noncarbonaceous materials is the German "Elfinal" [7] treatment of the molten magnesium with anhydrous ferric chloride.

Although numerous workers have investigated the problem of developing a fine-grained structure in magnesium castings, and many procedures have been recommended for the control of grain size, knowledge of the actual mechanism involved is far from complete. The fact that superheating and carbon treatments produce similar results and that both are effective only if aluminum is present have suggested that a compound containing aluminum or aluminum and carbon may be essential. Actually, aluminum carbide has been used for controlling grain size [2]. It appears probable that during the treatment some slightly soluble substance is absorbed, and precipitates as very fine particles throughout the melt in the early stages of solidification, to form the necessary nuclei. However, the identity of this substance has not been established.

During the course of an investigation at the National Bureau of Standards of the influence of melting and casting conditions on the properties of magnesium castings, a procedure for grain-size control was devised that appears promising be- 
cause of its simplicity. The procedure consists in treating the molten alloy with magnesite in lump form. In this paper a comparison is made of the results obtained when magnesium-alloy melts are superheated, treated with solid carbonaceous materials, with carbon monoxide, or with lump magnesite.

\section{Equipment and Procedure}

Most of the melts were made in a high-frequency induction furnace (960 cycles). The crucibles were of cast steel, $13 \mathrm{in}$. high and $10 \frac{1}{2} \mathrm{in}$. in outside diameter, with a wall thickness of $1 / 2$ in. The use of steel crucibles diminished the usual "coning up" of the molten charge in the high-frequency furnace and permitted the maintenance of an adequate flux cover on the melt. For comparison, a few melts were made in a gas-fired furnace with a steel crucible, and one special heat was made in a silicon carbide crucible in the high-frequency furnace.

Temperature measurements were made with an 18-gage Chromel-Alumel thermocouple, encased in a closed-end steel tube with an outside diameter of $5 / 16$ in. and a wall thickness of 0.025 in. The melting procedure was as follows:

A small quantity of $f_{\text {lux }}{ }^{2}$ was placed in the cold crucible, the metal charge was introduced, and additional flux was added as required during the melting. At approximately $730^{\circ} \mathrm{C}$, the molten metal was stirred and the surface dross was removed. In the superheating treatment flux was added, and the temperature was raised to $900^{\circ} \mathrm{C}$. This temperature was maintained for 15 minutes, after which the crucible was removed from the furnace and cooled to the pouring temperature $\left(760^{\circ} \mathrm{C}\right)$.

In the other treatments, the additions were made in the range from $730^{\circ}$ to $750^{\circ} \mathrm{C}$, and flux was added when necessary to avoid excessive oxidation. The temperature was than increased to between $760^{\circ}$ and $800^{\circ} \mathrm{C}$, after which the melt was cooled to the pouring temperature. All castings were poured at $760^{\circ} \mathrm{C}$, and during this operation the stream of metal was protected by the use of a dusting flux consisting of powdered boric acid and sulfur.

${ }^{2}$ A commercial produce known as $\mathrm{D}-310$ of the following composition $\mathrm{MgCl}_{2}, 50 \% ; \mathrm{KCl}, 20 \% ; \mathrm{CaF}_{2}, 15 \% ; \mathrm{MgO}, 15 \%$.
The castings were made in green sand molds, prepared from a sand formula suggested by Eastwood [8]. The mixture was as follows:

Washed silica sand (AFA fineness \#80)_ 91
Western bentonite
Powdered sulfur
Powdered boric acid
Ethylene glycol

After thorough mixing, tempering with 2.5 percent of water, and mulling, this sand had the following average properties:

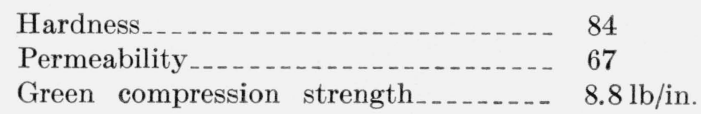

The mold surfaces were generally dusted lightly with powdered sulfur before the molds were closed.

The castings used for grain-size evaluation and for measurement of the tensile properties were tensile test bars of two types. The first were $3 / 4$ in.-diameter cylindrical bars that were subsequently machined into standard 0.505-in.-diameter tensile test bars. Bars of the second type were cast to this shape and dimension and were tested without machining.

Grain-size determinations were made on a transverse section of a test bar from each heat. To outline the primary crystals, the specimens were held at $385^{\circ} \mathrm{C}$ for 1 hour, cooled in an air blast, and etched with acetic picral etchant. ${ }^{3}$ Tests showed that the slight difference in diameter of the two types of test bars as cast did not affect the grain size appreciably.

The estimation of grain size was accomplished by comparing the microstructure at 100 magnifications with a chart [9] of structures with different average grain diameters. In the extremely coarse structures the approximate grain size was measured under low-power magnification.

The tests were performed on ASTM Alloy No. 4, a magnesium alloy widely used for generalpurpose sand-casting. The nominal composition of this alloy is as follows: Aluminum, 6 percent; zinc, 3 percent; manganese, 0.2 percent; balance, magnesium.

${ }^{3} 100 \mathrm{ml}$ of a freshly prepared solution of saturated picric acid in 95 percent alcohol, to which is added $10 \mathrm{ml}$ of glacial acetic acid. 


\section{Results}

\section{Treatments for Grain-Size Control}

Two melts were made to illustrate the coarse grain developed in the absence of any special treatment. In these runs, the 25 -lb melts were stirred, skimmed, and heated to about $785^{\circ} \mathrm{C}$, cooled to $760^{\circ} \mathrm{C}$, and poured. When the melt was made in the high-frequency induction furnace (melt 1, table 1) the cast test bars had an average grain size of 0.05 in., whereas in a duplicate melt (2) made in a gas-fired furnace, the average grain was $0.02 \mathrm{in}$. in diameter. It is possible that the finer grain of the latter may have been caused by absorption of carbonaceous gas from the furnace. However, the ultimate tensile strengths, 20,900 and $23,100 \mathrm{lb} / \mathrm{in}^{2}{ }^{2}$, are both characteristic of coarse-grained castings.

The effect of superheating to $900^{\circ} \mathrm{C}$ is shown in the results of melts 3,4 , and 5 recorded in table 1 . Superheating produced a uniformly fine grain of 0.004 and 0.005 -in. in diameter, regardless of whether the melt was made in the gas or induction furnace or whether the charge consisted of virgin or remelted metal. The results of the tensile tests illustrate the tendency toward somewhat higher values on cast-to-size bars over those that were machined. The ultimate tensile strengths for the machined bars from melts 3,4 , and 5 were nearly all in the range 26,000 to $27,000 \mathrm{lb} / \mathrm{in}^{2}$, whereas the values for the cast-to-size bars of melt 5 were approximately $3,000 \mathrm{lb} / \mathrm{in}^{2}{ }^{2}$ higher. The higher values obtained on the cast-to-size bars are probably due to the presence of a fine-grained surface layer or skin that is removed in the preparation of the machined specimens.

A study of the effectiveness of carbonaceous additions to the metal was made in melts 6 to 10 . The additions were made at $730^{\circ}$ to $750^{\circ} \mathrm{C}$. after which the melts were heated to $800^{\circ} \mathrm{C}$ and then cooled to the pouring temperature, as recommended by Mahoney, Tarr, and LeGrand [6]. The additions of from 0.2 to 0.8 percent of graphite to the melt were stirred in vigorously for 3 minutes. Small additions of flux were necessary to avoid burning in this operation. Neither the granular graphite (10 to 20 mesh) nor the powdered graphite (finer than 100 mesh) had the desired effect on the grain size of castings from melts 6 and 7 (average

TABLE 1.-Effect of various treatments of the molten metal on the grain size of the magnesium casting alloy, ASTM No. 4

\begin{tabular}{|c|c|c|c|c|c|c|}
\hline $\begin{array}{l}\text { Melt } \\
\text { No. }\end{array}$ & Treatment & $\begin{array}{c}\text { Grain size } \\
\text { (average } \\
\text { diameter) }\end{array}$ & Type of tensile bar & $\begin{array}{c}\text { Ultimate } \\
\text { tensile } \\
\text { strength }\end{array}$ & $\begin{array}{l}\text { Elonga- } \\
\text { tion }\end{array}$ & Remarks \\
\hline 1 & None.......... & $\begin{array}{l}\text { in. } \\
0.050\end{array}$ & Machined.... & $\begin{array}{r}l b . / i n .^{2} \\
20,900\end{array}$ & $\begin{array}{r}\text { Percent } \\
31 / 2\end{array}$ & \\
\hline 2 & - do & .020 & ..... do & 23,100 & 4 & Gas furnace. \\
\hline 3 & Superheated. . & .005 & ................. & 26,500 & 5 & \\
\hline 4 & do & .004 & _... do & 27,600 & 5 & Gas furnace. \\
\hline 5 & do & .005 & _. do & 26,300 & $41 / 2$ & Charge of remelt metal. \\
\hline 5 & …_do & .005 & Cast-to-size $\ldots . . . . . . . .$. & 30,100 & 6 & \\
\hline 6 & Granular graphite........... & .030 & Machined _.... & 21,800 & 3 & \\
\hline 7 & Powdered graphite & .030 & & ......... & $\ldots$ & \\
\hline 8 & Granular graphite & .014 & Machined...- & 23,900 & 4 & Gas furnace. \\
\hline 9 & Silicon carbide crucible & .006 & - n & -........... & $\ldots$ & Coarse grain, remelt metal. \\
\hline 10 & Carbon monoxide & .005 & Machined & 27,800 & $51 / 2$ & \\
\hline 11 & Magnesite ... & .005 & ..... do & 25,000 & 3 & \\
\hline 12 & do & .005 & do & 24,900 & 3 & \\
\hline 13 & _. do & .005 & _._. do & 27,100 & $31 / 2$ & \\
\hline 14 & do & .005 & do & 26,100 & $31 / 2$ & \\
\hline 15 & - do & .006 & _._. do & 23,900 & 3 & \\
\hline 16 & - do & .005 & _.._do_n_._. & 26,300 & $31 / 2$ & Coarse grain, remelt metal. \\
\hline 17 & do & .004 & Cast-to-size _............ & 29,800 & 6 & Miscellaneous remelt metal. \\
\hline 18 & - do & .004 & . do & 30,600 & $61 / 2$ & Do. \\
\hline 19 & - do & .006 & 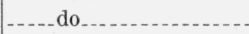 & 29,000 & $51 / 2$ & Do. \\
\hline 20 & do & .005 & do & 27,900 & 5 & Do. \\
\hline 21 & - do & .005 & ..... do & 29,000 & $51 / 2$ & Do. \\
\hline 22 & _ do & .005 & - do do & 30,200 & $61 / 2$ & Do. \\
\hline 23 & None & .040 & ..... do & & $\ldots$ & Remelt of castings from melt 3 . \\
\hline 24 & - do & .025 & . du & ......... & - & Remelt of castings from melt 10 . \\
\hline 25 & - do & .070 & do & 23,000 & 4 & Remelt of castings from melt 22 . \\
\hline
\end{tabular}


diameter, 0.030 in.). In contrast to these melts made in the induction furnace, the addition of granular graphite to melt 8 in a gas-fired furnace, produced a smaller grain size (0.014 in.). This again may be an effect of furnace atmosphere as suggested previously for melt 2 . It is believed that the relatively large grain size of the castings from melts 6,7 , and 8 was caused by inadequate contact between the molten alloy and the graphite particles, a condition that might be aggravated by the presence of liquid flux during the treatment.

Another procedure that has been suggested for obtaining better contact between the molten magnesium alloy and a carbon compound consists in making the melt in a silicon carbide crucible. This was tried in melt 9 , and the resulting castings indicated a grain size of 0.006 in. This procedure might be promising, except that the flux tends to penetrate and weaken the walls of the crucible.

The effectiveness of carbon monoxide treatment was demonstrated in melt 10, in which the gas was bubbled through the molten metal for 5 minutes at about $750^{\circ} \mathrm{C}$. This treatment produced a grain size of $0.005 \mathrm{in}$., and the tensile properties were equal to those obtained from superheated metal. These results are in agreement with those obtained by Nelson and Holdeman [5]. Apparently some of the carbon monoxide is reduced by the hot magnesium to form nascent carbon, the distribution of which throughout the melt is aided by the agitation produced by the gas bubbles. Carbon dioxide has been shown $[2,5,6]$ to be effective in the same manner. This gas can be generated by placing lumps of magnesite in the melt, thus eliminating the need for any special apparatus for the gas treatment.

The use of magnesite as a source of carbon for controlling grain size in magnesium castings was reported by Mahoney, Tarr, and LeGrand [6], who apparently used it in the same manner as other carbonaceous materials, that is, by stirring the powder into the melt. Natural lump magnesite, which has a specific gravity between 2.8 and 3.1, decomposes in the range $200^{\circ}$ to $750^{\circ} \mathrm{C}$ [10] and evolves carbon dioxide.

In order to evaluate the usefulness of lump magnesite for the control of grain size, white
California magnesite was used in a series of experiments. The regular melting practice was followed using a steel crucible in the high-frequency furnace.

The results for grain-size control through the use of magnesite are illustrated in melts 11 to 22 . In melt 11, approximately $75 \mathrm{~g}$ of magnesite, pea size and smaller, was added, but these small pieces remained on the top surface of the melt without the desired action. When a lump about 1 in. in diameter was added it sank into the melt at once and evolved carbon dioxide, which bubbled up to the surface. A thin flux cover was applied, and the decomposition of the magnesite continued for several minutes. The castings were poured at the usual temperature. Subsequent tests indicated an average grain size of $0.005 \mathrm{in}$., and tensile properties equivalent to those obtained by superheating.

Additional experiments showed that in some instances the gas evolution tended to float the magnesite, thus limiting the effectiveness of the gassing. This problem was solved by placing the magnesite, generally pieces about $3 / 4$ in. in diameter, in a perforated sheet-iron container that could be held at the bottom of the crucible. Fifty grams of magnesite was sufficient for the control of grain size in melts ranging from $18 \mathrm{lb}$. to the capacity of the crucible, $45 \mathrm{lb}$, and was equivalent to 0.25 to 0.60 percent of the weight of the charge. Treatment with less than $25 \mathrm{~g}$ of magnesite was inadequate even for a small charge. The procedure ultimately adopted was to stir and skim the melt at $730^{\circ} \mathrm{C}$, and immerse the magnesite for 5 minutes with flux additions as required. The temperature then was raised to $760^{\circ} \mathrm{C}$, and the metal was poured.

These experiments indicate that the use of lump magnesite does not introduce large inclusions into the melt, because the decomposition of the magnesite occurs with little change in physical form, and the resulting magnesia is retained in the perforated metal container. Microscopic examination (at $\times 100)$ of the sections used for grain size evaluation showed no evidence of magnesia inclusions.

Melts 11 to 15 were made with new ingot metal, 16 , was a remelt of coarse-grained metal, whereas 
mixed stock of both coarse and fine grain was remelted for heats 17 to 22 . Satisfactory fine grain was obtained in all cases, and the physical properties of the castings as indicated by tensile tests, were equal to those of superheated metal.

\section{Effect of Remelting Fine-grained Castings}

Fine-grained magnesium alloys do not always retain a fine structure after remelting. Mahoney, Tarr, and LeGrand [6] pointed out that the need for further grain-size control upon remelting was not as great with metal previously treated with carbon as with superheated ingot or scrap. Eastwood, Davis, and DeHaven [3] state that in their recommended procedure of passing a mixture of carbon tetrachloride and chlorine through the molten alloy, the tendency of the original melt to form fine grains is retained when the castings are remelted. Furthermore, they report that if an alloy is made from 25 percent or more of previously treated metal, the castings will have a fine grain.

A few experiments were included to ascertain the degree to which fine-grain characteristics were retained upon remelting. In melt 23 the charge consisted of metal from melt 3, which possessed an average grain size of 0.005 in., obtained by superheating. When the metal was melted, heated to $760^{\circ} \mathrm{C}$, and poured without any special treatment, the resulting grain size in the test casting was about $0.040 \mathrm{in}$., indicating complete loss of any tendency toward fine grain. Melt 24 was a similar remelt of metal from melt 10 , which had been treated with carbon monoxide and which had a grain size of 0.005 in. After remelting and recasting, a grain size of 0.025 in. was obtained. The fine-grained castings from melt 22, which had been treated with magnesite, were remelted in melt 25. Castings from this melt had an extremely coarse grain (0.070 in.). Thus, in each instance the tendency toward fine grain was lost upon remelting, regardless of the method by which fine grains were produced in the original melt.

\section{Discussion of Results}

The results verify previous reports on the effectiveness of using gaseous carbon compounds for the control of grain size in magnesium alloy castings. However, treatment with graphite, whether granular or powdered, did not produce the desired fine grain in test castings. The poor showing of this method was undoubtedly due to the difficulty of obtaining a satisfactory contact between the graphite and the molten alloy. The vigorous stirring required during the carbon addition favors oxidation of the metal, and flux additions to control the oxidation appear to limit the action of the carbon. When gaseous carbon compounds are bubbled through molten metal it is thoroughly stirred, and the reducing action of the magnesium apparently produces carbon in a form that can be readily absorbed by the alloy.

The treatment with lump magnesite eliminates the need for the equipment required to bubble gas through a melt and gives the same action and effect as when a gassing treatment is used. The magnesite is inexpensive, can be stored conveniently, and is simple to use. These advantages suggest applications of the method particularly in foundries that operate on a small scale or do not work continuously with magnesium, and where it is desired to obtain fine-grained castings without resorting to superheating or to more elaborate equipment for grain-size control.

The tensile properties of castings produced by the various treatments for grain-size control, shown in table 1, demonstrate the advantage of fine grain, no matter how it is obtained. The highest ultimate tensile strengths were obtained from castings having a grain size of the order of 0.005 in.

The results obtained in remelting fine-grained castings produced from metal that had been superheated, treated with carbon monoxide or with magnesite, indicate that with the technics used in this investigation, the fine-grain characteristics of a magnesium casting are lost when the metal is remelted. The difference between the results for carbon monoxide or magnesite treatments and for those reported elsewhere for carbon tetrachloride-chlorine-treated alloys, is difficult to explain, in view of the fact that the control of grain size in each case has been attributed to the effect of carbon.

The authors gratefully acknowledge the assistance of R. H. Harwell and W. P. Saunders in the experimental work of this investigation. 


\section{References}

[1] I. G. Farbenindustrie Aktiengesellschaft, British Patent No. 359425, Process for improving the mechanical properties of magnesium alloys (1931).

[2] J. A. Davis, L. W. Eastwood, and James De Haven, Am. Foundryman 8, 34 (1945); Restricted Reports OPRD, Project No. NRC-546 conducted at Battelle Memorial Institute (1944-45).

[3] L. W. Eastwood, J. A. Davis, and J. C. De Haven, Light Metal Age 4, 8 (Feb. 1946).

[4] Ralph Hultgren and D. W. Mitchell, Trans. Am. Inst. Mining Met. Engrs. 161, (Inst. of Metals Div. 323, 1945).
[5] C. E. Nelson and G. E. Holdeman, U. S. Patent No. 2,380,863 (July 31, 1945).

[6] C. H. Mahoney, A. L. Tarr, and P. E. LeGrand, Trans. Am. Inst. Mining and Met. Engrs. 161, (Inst. of Metals Div. 328, 1945).

[7] The German Magnesium Industry, reported by W. E. McConnica, Technical Intelligence Report, Office of the Chief Quartermaster, p. 5, 41, 67.

[8] L. W. Eastwood, Foundry 73, 80 (Jan. 1945).

[9] P. F. George, AST M Bulletin No. 129 (Aug. 1944).

[10] J. W. Mellor, A comprehensive treatise on inorganic and theoretical chemistry, IV, 349 (Longmans, Green, and Co., New York and London, 1934).

Washington, June 10, 1947. 